\title{
BREAKING THE WAVES: A POISSON REgResSiON APPROACH TO SCHUMPETERIAN CLUSTERING OF BASIC INNOVATIONS
}

\author{
by \\ Gerald Silverberg* \& Bart Verspagen** \\ * MERIT, Maastricht University \& International Institute of Infonomics (III), \\ gerald.silverberg@merit.unimaas.nl, meritbbs.unimaas.nl/staff/silverb.html \\ ** Corresponding author, ECIS, Eindhoven University of Technology, \\ b.verspagen@tm.tue.nl,www.tm.tue.nl/ecis/bart/
}

Fourth draft.

We are indebted to Bart Los and Witold Kwasnicki for helpful discussions, and two anonymous referees for helpful comments. Only the authors are to be blamed for any controversial opinions or remaining errors, however.

\begin{abstract}
:
The Schumpeterian theory of long waves has given rise to an intense debate on the existence of clusters of basic innovations. Silverberg and Lehnert have criticized the empirical part of this literature on several methodological accounts. In this paper, we propose the methodology of Poisson regression as a logical way to incorporate this criticism. We construct a new time series for basic innovations (based on previously used time series), and use this to test the hypothesis that basic innovations cluster in time. We define the concept of clustering in various precise ways before undertaking the statistical tests. The evidence we find only supports the 'weakest' of our clustering hypotheses, i.e., that the data display overdispersion. We thus conclude that the authors who have argued that a long wave in economic life is driven by clusters of basic innovations have stretched the statistical evidence too far.
\end{abstract}

JEL Codes: O3, O4, N10

ECIS - Eindhoven Center for Innovation Studies, PO Box 513, 5600 MB Eindhoven, the Netherlands, fax +31 402474646

MERIT - Maastricht Economic Research Institute on Innovation and Technology, PO Box 616, 6200 MD Maastricht, the Netherlands, fax +31 433884905

III - International Institute of Infonomics, PO Box 2606, 6401 DC Heerlen, the Netherlands 


\section{Introduction}

Schumpeter was the first economist to place the mechanism of basic innovation in the center of the discussion about the long-run development pattern of global capitalism. His emphasis on the clustering of basic innovations ${ }^{1}$ is the centrepiece of his theory of long-term economic development expounded at great length in his Business Cycles (Schumpeter 1939). The introduction of radical innovations triggers a wave of economic activity involving investmentbased diffusion driven by temporary monopoly profits and bandwagon-like imitation by other entrepreneurs known as the process of creative destruction. Schumpeter asserted that this process inexorably led to the type of long waves Kondratieff (1926/1935) had claimed to have discovered in the historical data. While his vision was challenged at the time by, for example, Kuznets (1940), Mensch (1975/1979) revived the discussion on clustering of innovations and economic activity using new data and an original hypothesis about causality. This sparked an intensive empirical debate, partly in the pages of this journal, in the 1980s. Thus the status of the clustering issue has remained a key concept in the debate about long waves and their explication. ${ }^{2}$

The relationship between innovation and long waves is not just a matter of idle historical curiosity. The publicity surrounding the so-called "new" economy (information and communication technology, the Internet) as an apparent golden era which seemingly repeals the constraints of the "old" economy, is a case in point. Does ICT usher in an upswing in economic activity and productivity growth that suspends the orthodox wisdom about the relationship between, for example, employment and inflation, or the fair valuation of equities, or is it only a rerun of previous historical experience with revolutionary and pervasive innovations? Ten Raa and Wolff (2000), for example, find strong productivity effects related to ICT, while Gordon (2000) is much more skeptical after a comparison of the productivity gains of ICT with those of previous technological revolutions.

The perspective of long waves also raises the question as to whether the (supposed) productivity increases related to ICT represent a permanent increment in the long-term rate of technical change, or are simply a passing cyclical phenomenon. The long wave view would hold that the current period of strong growth is the upswing of the fifth long wave, and, hence, that a downswing would inevitably follow upon it. ${ }^{3}$ The two views are not mutually exclusive. One

\footnotetext{
1 "[Innovations] are not evenly distributed in time, but that on the contrary they tend to cluster, to come about in bunches, simply because first some, and then most firms follow in the wake of successful innovation" (Schumpeter, 1939, p. 75).

${ }^{2}$ However, Silverberg and Lehnert (1993), in a formal model, demonstrated that such clustering was not logically necessary to produce long-period quasi-cyclical behavior of a Schumpeterian economy even while their empirical analysis did point to non-uniform arrival rates of innovations.

${ }^{3}$ In his historical analysis, Schumpeter observed three long waves since the beginning of modern capitalism. Freeman and Soete (1997), in a similar vein, take note of five long waves, i.e., they argue that two new ones have occurred since the end of Schumpeter's analysis.
} 
may imagine the long-run rate of basic innovations as a process with both a positive trend and a cyclical component. In this case, the relevant question becomes whether a model can be formulated that identifies both elements simultaneously.

After a long period of quiescence, a new debate on Schumpeter's hypothesis arose in the 1970s and 1980s. In this debate, which is summarized in some detail below, much of the empirical argument centered around time series of basic innovations. ${ }^{4}$ These were collected by various authors (who obtained somewhat varying results) on the basis of an historical evaluation of the importance of innovations. The main research question for these authors was whether the number of basic innovations was higher in depression periods than in prosperity periods (a more specific hypothesis than Schumpeter put forward, since he did not relate clustering to specific phases of the economic cycle). The possibility of a (very) long-run trend in the rate of basic innovation did not play any explicit role in this debate.

As early as 1974, Sahal (1974) suggested using a statistical method based on the Poisson and negative binomial distributions to describe time series of incremental innovation. However, this was not taken up in subsequent studies by Kleinknecht (1990) and Solomou (1986), who relied instead on statistical methods based on the normal distribution. Silverberg and Lehnert (1993) highlighted this error and employed more appropriate nonparametric tests based on the Poisson process. In the mean time, Poisson regression has become a standard part of the econometric toolbox (see, e.g., Green, 1995). Applying this method, the question of whether Schumpeter was right (i.e., basic innovations tend to cluster) can be analyzed simultaneously with the question of whether the long-run rate of occurrence of basic innovations is rising. This is what this paper intends to do, working with the same basic innovation databases used by authors such as Kleinknecht and Mensch in the 1970s and 1980s.

The rest of this paper is organized as follows. In Section 2, the empirical literature on basic innovation time series and long waves will be briefly reviewed and criticized. On the basis of these results a number of explicit statistical hypotheses are formulated to capture the ideas that have only been implicit until now in the debate on Schumpeterian basic innovations. Section 3 implements this model in the context of several time series for basic innovations, estimating a model admitting both overdispersion (clustering) and trend components. Section 4 summarizes the main findings, and draws some conclusions. The two annexes present technical details of the econometric methods and our recompilation of the innovation data.

\section{Innovation time series: Review of the literature and shortcomings}

The 1970s and 1980s witnessed a rekindling of the debate on the Schumpeterian hypothesis of clustering of innovations rooted in statistical analysis of real data. The first contribution to this

\footnotetext{
${ }^{4}$ Schumpeter distinguished between inventions and innovations, the latter denoting the point in time at which the technology is successfully commercialized.
} 
debate was Mensch (1975/1979), who argued strongly in favour of the Schumpeterian hypothesis that basic innovations tend to be clustered. Moreover he claimed that this clustering occurs in the depression periods of the long wave. Mensch's theoretical explanation for such clustering was that only in the despair of the depression phase do firms resort to the highly risky strategy of introducing basic innovations (drawing on inventions that may have been made previously). During the upswing and upper turning phase, in contrast, firms focus on squeezing profits out of the dominant technologies, and search activities aimed at basic innovations are at a low level (whether this is perfectly rational or myopic behavior with respect to the relative costs of the various technological opportunities over the cycle remains open). His approach was to construct a database of basic innovations, and to use a runs test on the resulting time series of the number of innovations occurring each year (using year of innovation rather than year of invention) to test whether the series clustered. A runs test is a test of independence on the assumption of identical distribution, and thus does not control for a trend. On the other hand, it does not require the researcher to impose a periodization on the data, a defect which, as we shall see, mars the work of later researchers.

While Mensch drew on the work of Jewkes, Sawers and Stillerman (1958) for his time series, that work was not constructed to be representative, and in particular the datings used and choice of innovations were disputed by Freeman, Clark, and Soete (1982). All such innovation time series, including the ones used below, are naturally subject to limitations. The first limitation concerns the arbitrariness in the selection of innovations and their dates. Second, an end of sample bias may exist since there usually is insufficient evidence to identify which innovations actually prove to be economically significant in the period close to the researcher's own epoch. Finally, a simple listing of innovations fails to capture their systemic and paradigmatic interrelatedness, the importance of which has been emphasized by Freeman and Perez (1988).

Haustein and Neuwirth (1982) compiled a different time series on basic innovations, and used spectral analysis to test for periodicity in this and other time series related to the long wave. They concluded that there are "some doubts when looking at the regular patterns of inventions and innovations by Mensch and Marchetti” (p. 67). In other words, their results suggest a less strictly periodic pattern than was suggested by Mensch.

In the mean time, the interpretation of the innovation time series data by Mensch gained support from Van Duijn (1983) and Kleinknecht (1981, 1987), who provided more extensive data sets. A further contribution that was critical of the clustering hypothesis was Solomou (1986). He applied a $z$-test to the null hypothesis that the mean number of basic innovations in adjacent periods were drawn from a normal distribution with the same mean, which could not be rejected.

Kleinknecht (1990) responded to this criticism by constructing a new time series of basic innovations that was a compilation of three different time series used earlier (Mensch, Haustein and Neuwirth, Van Duijn). He used a similar null-hypothesis as Solomou, but relied on a $t$-test rather than a $z$-test. His conclusions were strongly in favour of clustering of basic innovations in the depression periods of the long wave. An important element of the differences in the results 
between Kleinknecht and Solomou lies in the different periodizations they use (as admitted by Kleinknecht, 1990, p. 86). Both Solomou and Kleinknecht use a division of a full cycle into two periods (up and down). Solomou (1986) uses the periodization proposed by Mensch(1975/1979), while Kleinknecht (1990) relies on two different periodizations (for different lead times of innovation to economic time series), which were both based on his own work (Kleinknecht, 1987).

The methodology of these studies was strongly criticized by Silverberg and Lehnert (1993). They argue that

" $z$ and $t$ tests ... are only applicable to a normally distributed random variable. On a priori grounds we have argued that the null hypothesis on innovations must be that they are homogeneous Poisson distributed, however, and a histogram of, for example, the Haustein and Neuwirth data (as well as any of the other series we have examined) confirms that they are anything but normally distributed ... both authors apply their tests to sub samples they claim have been selected on a priori criteria ... In general, the periodisations employed derive from previous authors such as Mensch, whose use of a runs test did not depend on it, or on the examination of growth rates and the addition of a time lag ... growth rates and a moving average of the innovation data may be highly (cross) correlated, so that the selection of a proper lag against variations in the growth rate series may simply be a method to select sub periods of above- and below-average innovation activity even from a completely random series. This fact would further invalidate any means test (even one appropriate to a Poisson process, such as a binomial statistic)". (p. 31)

Thus, the statistical methodology used by Solomou and Kleinknecht is flawed, both with regard to the assumed distribution underlying the test statistics, and the particular choice of a periodization scheme. To overcome these difficulties, Silverberg and Lehnert apply a number of nonparametric tests to the null of a homogeneous Poisson process without imposing a periodization on the time series. This is convincingly rejected for all series. They then test for the existence of an exponential trend, again using a nonparametric method appropriate for a Poisson process, and show such a trend to be highly significant for all series. The growth rate of the trend is estimated (on the assumption of a nonhomogeneous Poisson process with exponentially growing arrival rate) and found to be in the range $1 / 2$ to $1 \%$ per annum, depending on the series examined. After eliminating the trend from the data by a process of exponential slowing down of the original time series, the resulting trendless series are still shown to deviate significantly (although less so than non-detrended data) from a time-homogeneous (i.e., nonclustering) Poisson distribution. They concluded that, while to a first approximation these count data appeared to be generated by a Poisson process with exponentially growing trend, it can not be determined with these methods whether the statistically significant remaining deviations where indeed periodic or were random clustering resulting from some point process other than Poisson (e.g., negative 
binomial). They suggest further research using a more elaborate modeling strategy based on the Poisson distribution (p. 33) to carry this line of inquiry further.

This advance in the methodological discussion forces us to confront the question of what explicit statistical hypothesis actually corresponds to the Schumpeterian theory of basic innovation, since different variants are conceivable that necessitate different statistical tests. One particularly strong hypothesis, which we will term the Schumpeter Mark I.0, seems to be implicit in most of the empirical work, although it is not necessarily attributable to Schumpeter himself. This hypothesis might be formulated as follows. Basic innovations are generated by a stochastic process, but one whose arrival rate fluctuates deterministically and strictly periodically with a period of 50-60 years.

A more involved version of this hypothesis, which we will refer to as Schumpeter Mark I.1, also claims that the arrival rate varies deterministically, but as a function of macroeconomic variables such as the profit rate. The arrival rate will thus have time series properties similar to those of such variables and correlate with them, but not necessarily be strictly periodic. Which way causality runs will be difficult to determine (with Mensch arguing from macroeconomic variables to innovation back to macroeconomic variables, while Schumpeter, as near as we can make out, would only argue from innovation clusters to macroeconomic growth). If the macroeconomy is in fact more or less periodic, then the Schumpeter Mark I.0 and I.1 hypotheses will be almost impossible to distinguish.

Schumpeter (1939) himself appears to argue only that innovations cluster, without any reference to a specific deterministic structure determining when exactly clusters of innovations will occur in time (i.e., in which phase of the economic wave, or even in regularly spaced spells of high and low innovation activity). Such a 'weak' variant of clustering may be consistent with a random clustering pattern, i.e., periods of high and low innovation activity do occur in the data, but there is no regular and predictable mechanism governing their occurrence. We will classify hypotheses of this kind as Schumpeter Mark II: the stochastic process generating innovations is more complicated than Poisson and clusters arrive stochastically. ${ }^{5}$ Two variants can be differentiated. Mark II.0 invokes purely random clustering from some additional distribution (such as a negative binomial process where the arrival rate fluctuates according to a Gamma distribution; see Annex I and below). Mark II.1 calls for the clustering to be initiated by random events, but then obey some sort of causal mechanism that makes this random event 'persist' for some time. An example of such a process would be an autoregressive process, in which (with positive autocorrelation) a single random event tends to be followed by higher activity in the periods immediately following. To see how such a hypothesis might be consistent with at least part of Schumpeter's arguments, recall the quotation from Schumpeter (1939) in footnote 1.

\footnotetext{
${ }^{5}$ In particular: the stochastic process is overdispersed, a term to be explained below.
} 


\section{Empirical results}

As we have argued above, innovations are intrinsically count data generated by a point process. Sahal (1974) proposed using the Poisson model to examine the characteristics of various time series of innovations in different industries. His conclusion was that "invention is properly characterized as a Poisson random process, but [...] its rate is a function of economic forces" ( $p$. 403). Although Sahal did provide some estimates of parameters related to these economic forces, these were based on ordinary least square methods. However, when the data contain many zero and small integer values, a maximum likelihood approach based explicitly on the Poisson distribution is more appropriate. Such a procedure was introduced into the literature on innovation by Hausman, Hall and Griliches (1984). They estimated a model in which the number of patents of a firm is related to the firm's R\&D expenditures. Elaborations on this approach were presented by Crepon and Duguet (1997a, b) and Cincera (1997).

The methods used in this literature, commonly known as 'Poisson regression', are presented in Annex I below. The annex also presents an extension of the methods of Poisson regression to time series analysis, which is of particular importance to the problem at hand. Our aim in this paper will be to apply these statistical tools to the investigation of the hypotheses formulated above.

Like Kleinknecht (1990), we will use a time series for basic innovations that is created from several other time series introduced by other researchers. This new innovation time series was created by merging the two longest time series available in the literature, i.e., Haustein and Neuwirth's and Van Duijn's. Kleinknecht's's time series is too short compared to the two other basic innovation time series. Besides the innovations time series, we will also use the time series of important patents as identified by Baker (1976), which was also used by Kleinknecht (1987). The Baker data were not included in the merged innovation time series because they are based on patent data rather than innovation data, and hence are less compatible with the other two time series. Instead, the Baker time series will be treated separately in the statistical analysis.

The construction of our merged innovation time series differs substantially from the Kleinknecht approach. The main difference concerns the overlap, i.e., those innovations which are covered in both sources. Kleinknecht constructs a time series in which the innovations that occur more than once in the three time series he considers are double or triple counted. In other words, he simply adds up the numbers of innovations per year in the three innovation time series. Kleinknecht justifies this procedure by arguing that it provides some implicit weighting scheme, in which the important innovations (i.e., those on which all sources agree) are weighted more heavily.

It is clear that such an implicit weighting procedure introduces an element of extreme arbitrariness. We choose instead to count an innovation only once even if it is covered by both samples. A complication in this procedure is that, as noted by Kleinknecht, the innovation dates of the same innovation often differ between the two sources. The majority of overlap cases are 
dated within a range of 10 years, but differences of up to 50 years exist. In all cases, the earliest date was used to assign the innovation to the merged sample. The merged sample contains 88 innovations that occur in both samples, 90 innovations that only occur in the Haustein and Neuwirth sample, and 70 cases that are only listed in the Van Duijn sample. The merged series thus has 248 innovations, dating from 1764 to 1976 . The complete listing of all innovations in the merged sample, as well as the original Haustein and Neuwirth and Van Duijn sources, together with their assignment to the merged sample, are given in Annex II. Following Kleinknecht's terminology, we will refer to this merged time series as the 'supersample time series'.

Figure 1 shows histograms for the Baker patent time series, the two time series we used to create the 'supersample time series' (Haustein \& Neuwirth and Van Duijn), and the 'supersample time series'. The Baker time series runs from 1769 until 1970, and thus comprises 202 years. The Haustein and Neuwirth (1982) data run from 1764 until 1975 (212 years), while Van Duijn (1983) covers the period 1811 - 1971 (161 years).

All three histograms show that the highest frequency is found for zero innovations. Also, all histograms show mostly declining frequencies for larger numbers of innovations per year. No time series shows more than seven innovations per year (this occurs twice in the Haustein and Neuwirth series). The assumption of normally distributed data clearly must be rejected at face value.

As is explained in Annex I in more detail, Poisson regression is a technique aimed at estimating the arrival rate of a certain event. In the present context, the arrival rate can be thought of as the average number of basic innovations per year. It can either be modeled as a constant factor, or as dependent on economic variables as well as time. We start by fitting a simple Poisson model with a constant arrival rate (i.e., a time-homogenous process), and then proceed to implement two departures from this simple model. The first generalizes the Poisson model to allow the variance of the dependent variable to be larger than the mean (this phenomenon is known as overdispersion, and is discussed in Annex I). This is done by fitting a negative binomial model. The second is to estimate the arrival rates (in both the Poisson and the negative binomial model) as following a time trend. The latter is specified by equating the $\log$ of the arrival rate to a polynomial function of time, where we experiment with polynomial degrees up to 3 (a $\log$ formulation is used to ensure that the arrival rate is always nonnegative). ${ }^{6}$ The results of these estimations are displayed in Table 1.

\footnotetext{
${ }^{6}$ In the notation of Annex I, we thus estimate $\ln \lambda=c+\beta_{1} t+\beta_{2} t^{2}+\beta_{3} t^{3}$ (where $t$ is time and we set some of the higher order $\beta$ s to zero in some estimations).
} 

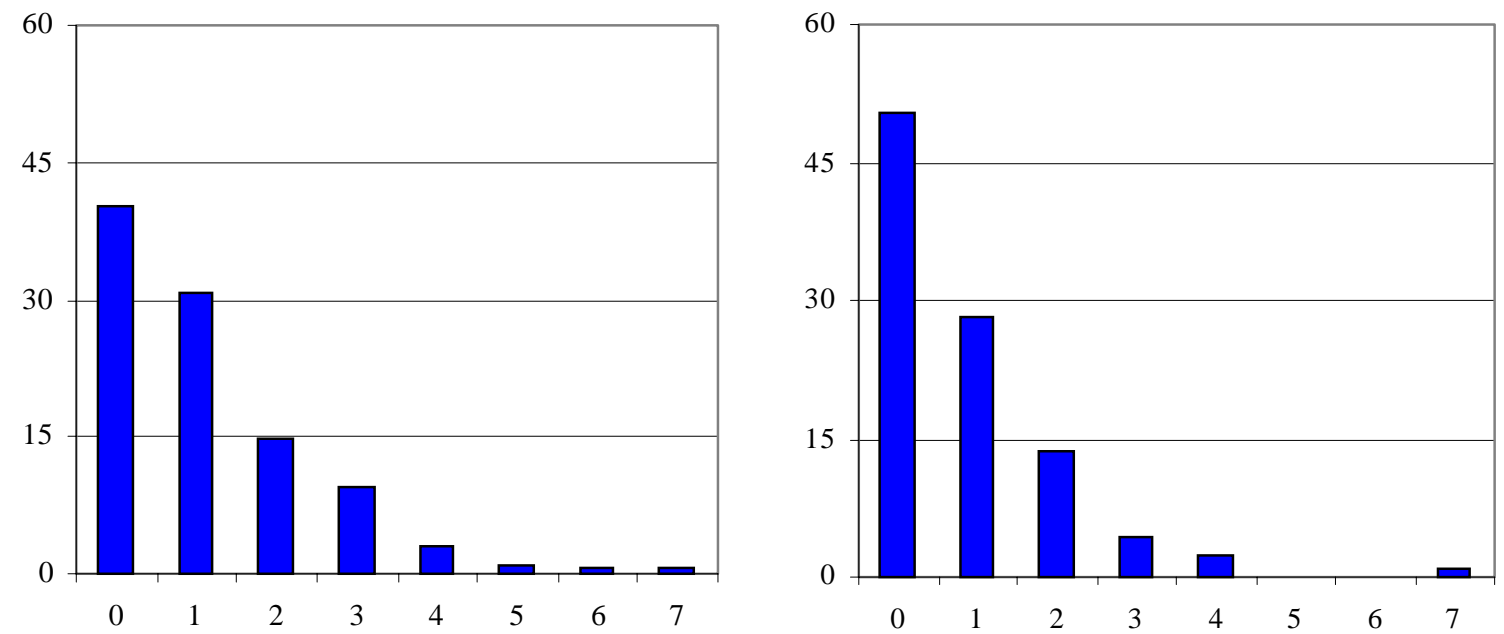

Van Duijn

Super sample
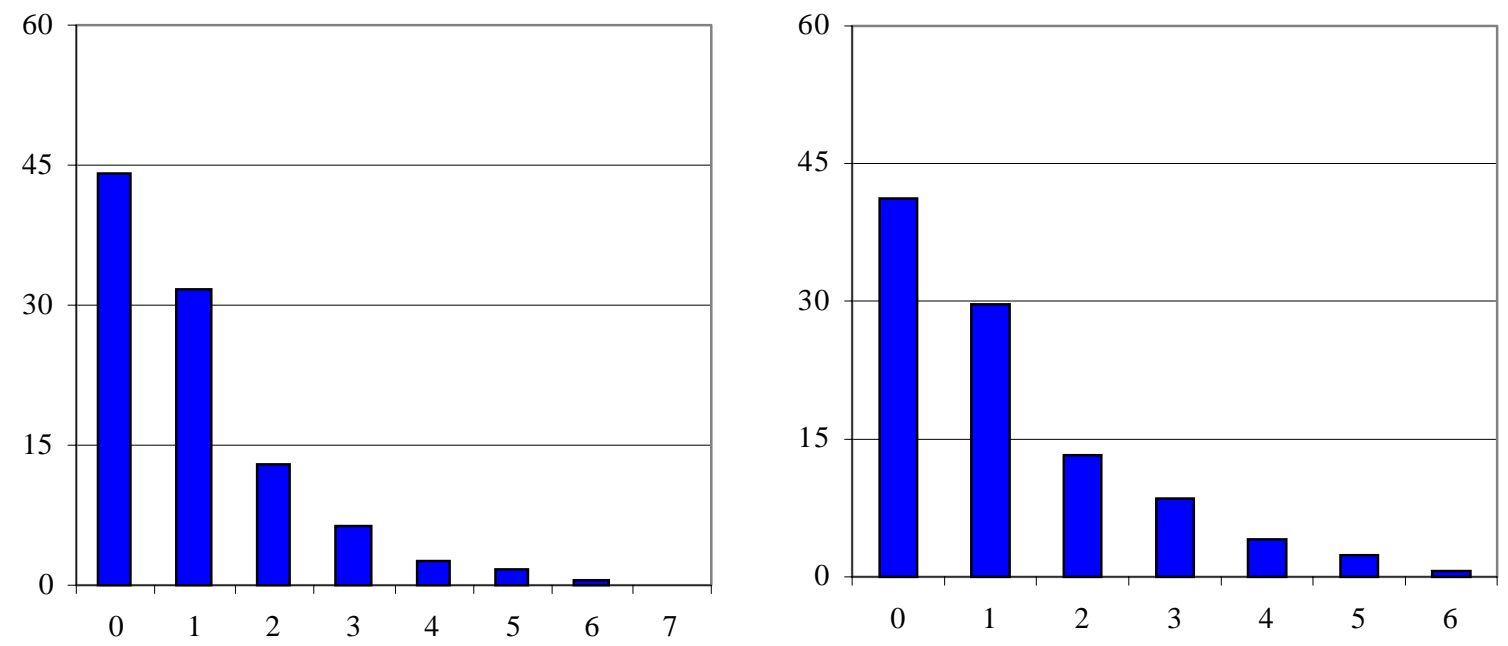

Figure 1. Histograms of basic innovation time series data, on horizontal axis: number of innovations per year; on vertical axis: percentage share of total sample 
Table 1. Regression results, Poisson and Negative Binomial models, arrival rate function of time

\begin{tabular}{|c|c|c|c|c|c|c|c|c|c|c|}
\hline $\begin{array}{l}\text { Innovation } \\
\text { Data Source }\end{array}$ & & $\begin{array}{r}\text { Start } \\
\text { year }\end{array}$ & $c$ & $\beta_{1}$ & $\beta_{2}$ & $\beta_{3}$ & $\alpha$ & $\log 1$ & SQ & Q \\
\hline Innovations & 213 & 1764 & $\begin{array}{l}0.1521 \\
(0.000)\end{array}$ & & & & & -331.654 & $* * *$ & $* * *$ \\
\hline Innovations & 213 & 1764 & $\begin{array}{l}0.1521 \\
(0.069)\end{array}$ & & & & $\begin{array}{c}0.6087 \\
(0.000)\end{array}$ & -316.186 & $* * *$ & $* * *$ \\
\hline Innovations & 213 & 1764 & $\begin{array}{r}-1.0568 \\
(0.000)\end{array}$ & $\begin{array}{l}0.9692^{\mathrm{a}} \\
(0.000)\end{array}$ & & & & -291.823 & $* *$ & $* *$ \\
\hline Innovations & 213 & 1764 & $\begin{array}{r}-1.1420 \\
(0.000)\end{array}$ & $\begin{array}{l}0.0104 \\
(0.000)\end{array}$ & & & $\begin{array}{c}0.2662 \\
(0.023)\end{array}$ & -286.994 & $* *$ & $* *$ \\
\hline Innovations & 213 & 1764 & $\begin{array}{r}-2.5467 \\
(0.000)\end{array}$ & $\begin{array}{l}0.0389 \\
(0.000)\end{array}$ & $\begin{array}{r}-0.1168^{b} \\
(0.000)\end{array}$ & & & -279.317 & & \\
\hline Innovations & 213 & 1764 & $\begin{array}{r}-2.5702 \\
(0.000)\end{array}$ & $\begin{array}{l}0.0393 \\
(0.000)\end{array}$ & $\begin{array}{r}-0.1186^{b} \\
(0.000)\end{array}$ & & $\begin{array}{c}0.1744 \\
(0.077)\end{array}$ & -276.876 & & \\
\hline Innovations & 213 & 1764 & $\begin{array}{r}-2.6012 \\
(0.000)\end{array}$ & $\begin{array}{l}0.0408 \\
(0.028)\end{array}$ & $\begin{array}{r}-0.1347^{\mathrm{b}} \\
(0.410)\end{array}$ & $\begin{array}{l}0.4946^{\mathrm{e}} \\
(0.912)\end{array}$ & & -279.311 & & \\
\hline Innovations & 213 & 1764 & $\begin{array}{l}-2.6159 \\
(0.000)\end{array}$ & $\begin{array}{l}0.0410 \\
(0.044)\end{array}$ & $\begin{array}{r}-0.1351^{b} \\
(0.465)\end{array}$ & $\begin{array}{l}0.4669^{\mathrm{e}} \\
(0.928)\end{array}$ & $\begin{array}{c}0.1742 \\
(0.077)\end{array}$ & -276.872 & & \\
\hline Baker patents & 202 & 1769 & $\begin{array}{l}0.1123 \\
(0.041)\end{array}$ & & & & & -299.213 & $* * *$ & $* * *$ \\
\hline Baker patents & 202 & 1769 & $\begin{array}{l}0.1123 \\
(0.166)\end{array}$ & & & & $\begin{array}{c}0.4254 \\
(0.005)\end{array}$ & -291.537 & $* * *$ & $* * *$ \\
\hline Baker patents & 202 & 1769 & $\begin{array}{r}-0.7487 \\
(0.000)\end{array}$ & $\begin{array}{l}0.7256^{a} \\
(0.000)\end{array}$ & & & & -279.997 & $* * *$ & $* * *$ \\
\hline Baker patents & 202 & 1769 & $\begin{array}{r}-0.7867 \\
(0.000)\end{array}$ & $\begin{array}{l}0.7577^{a} \\
(0.000)\end{array}$ & & & $\begin{array}{c}0.2422 \\
(0.059)\end{array}$ & -276.740 & $* * *$ & $* *$ \\
\hline Baker patents & 202 & 1769 & $\begin{array}{r}-1.6670 \\
(0.000)\end{array}$ & $\begin{array}{l}0.0269 \\
(0.000)\end{array}$ & $\begin{array}{r}-0.8347^{\mathrm{c}} \\
(0.000)\end{array}$ & & & -274.230 & $* *$ & $*$ \\
\hline Baker patents & 202 & 1769 & $\begin{array}{r}-1.6616 \\
(0.000)\end{array}$ & $\begin{array}{l}0.0268 \\
(0.000)\end{array}$ & $\begin{array}{r}-0.8268^{c} \\
(0.001)\end{array}$ & & $\begin{array}{c}0.1876 \\
(0.110)\end{array}$ & -272.086 & $* *$ & $*$ \\
\hline Baker patents & 202 & 1769 & $\begin{array}{r}-1.7662 \\
(0.000)\end{array}$ & $\begin{array}{l}0.0308 \\
(0.029)\end{array}$ & $\begin{array}{r}-0.1225^{\mathrm{b}} \\
(0.366)\end{array}$ & $\begin{array}{l}0.1133^{\mathrm{d}} \\
(0.769)\end{array}$ & & -274.204 & $* *$ & $*$ \\
\hline Baker patents & 202 & 1769 & $\begin{array}{r}-1.7267 \\
(0.000)\end{array}$ & $\begin{array}{l}0.0294 \\
(0.068)\end{array}$ & $\begin{array}{r}-0.1093^{b} \\
(0.491)\end{array}$ & $\begin{array}{l}0.7774^{\mathrm{d}} \\
(0.866) \\
\end{array}$ & $\begin{array}{r}0.1870 \\
(0.112)\end{array}$ & -272.076 & $* *$ & $*$ \\
\hline
\end{tabular}

Notes: $\beta_{1}, \beta_{2}$ and $\beta_{3}$ are the coefficients on the polynomials of time $\left(1^{\text {st }}, 2^{\text {nd }}\right.$ and $3^{\text {rd }}$ degree, respectively). $\alpha$ is the parameter for overdispersion in the negative binomial model. Estimated coefficients are equal to documented coefficients divided by the following factors (absence of a note indicates estimated coefficient is equal to documented coefficient): ${ }^{\mathrm{a}} 100,{ }^{\mathrm{b}} 1000,{ }^{\mathrm{c}} 10000,{ }^{\mathrm{d}} 1000000,{ }^{\mathrm{e}} 10000000 . \mathrm{N}$ is the number of observations. Numbers between brackets are p-values associated with the $t$-statistics. One, two and three stars point to rejection at the 10, 5 or $1 \%$ level, respectively, for a $\chi^{2}$-test of the null-hypothesis "all autocorrelations of the residuals up to this order are zero". Column SQ gives the statistic suggested by Cameron \& Travedi, p. 229. Column Q gives the Box-Ljung statistic. All residuals used in these tests are standardized. 
The hypothesis of a constant arrival rate (time-homogenous Poisson process, or all polynomial terms equal to zero) is obviously rejected. Both for the supersample innovations time series and the Baker patents time series, the exponential quadratic trend emerges as the 'best' model. Entering the third-order term only leaves the linear trend significant, while a second-order polynomial emerges with time-related terms significant. We thus proceed on the assumption that a quadratic trend captures the long-run growth rate of the number of basic innovations in a reasonable way.

Figure 2 displays the raw data and the fitted linear and quadratic exponential trends for the two models (Poisson and negative binomial). The monotonically increasing lines are the fitted linear trends, the lines leveling off towards the end of the period are the estimated quadratic trends. The estimated trends do not differ greatly between the pure Poisson and the negative binomial models. There is, however, a major difference between the linear and quadratic trends. The latter shows a higher level during the period (roughly) 1850 until 1900, and levels off around 1930 (supersample) or 1920 (Baker patents). This would seem to indicate that the rate of basic innovation is slowing down in the $20^{\text {th }}$ century after a period of relatively rapid increase in the latter part of the $19^{\text {th }}$ century. This phenomenon may, however, be caused by an end of sample bias in the time series caused by the fact that at the time when the time series were constructed (during the 1970s), it was not yet clear which recent innovations would prove to be basic.

Overdispersion is measured by the significance of the parameter $\alpha$ in the negative binomial model (see Annex I for details). The results differ somewhat between the two time series in this respect. In the case of the supersample of innovations, the negative binomial model is always preferred to the simple Poisson model, as is clear from the fact that the $\alpha$ parameter is always significant (at the 10\% level). In the case of the Baker patent time series, the quadratic and cubic models both yield $\alpha$ s that are significant at a level just above $10 \%$, while the linear exponential trend ( $10 \%$ level) model and the time-homogenous process ( $1 \%$ level) yield significant $\alpha$ s.

These results have implications for the hypotheses that were introduced above. Specifically, the fact that the negative binomial model is generally preferred over the simple Poisson model points to the fact that the data are in fact overdispersed. In other words, compared to a (timehomogenous) Poisson process, the data display clustering in the sense of random spells of high and low innovation activity. We interpret this as evidence in favour of the Schumpeter Mark II.0 hypothesis. 
(a) Innovation supersample

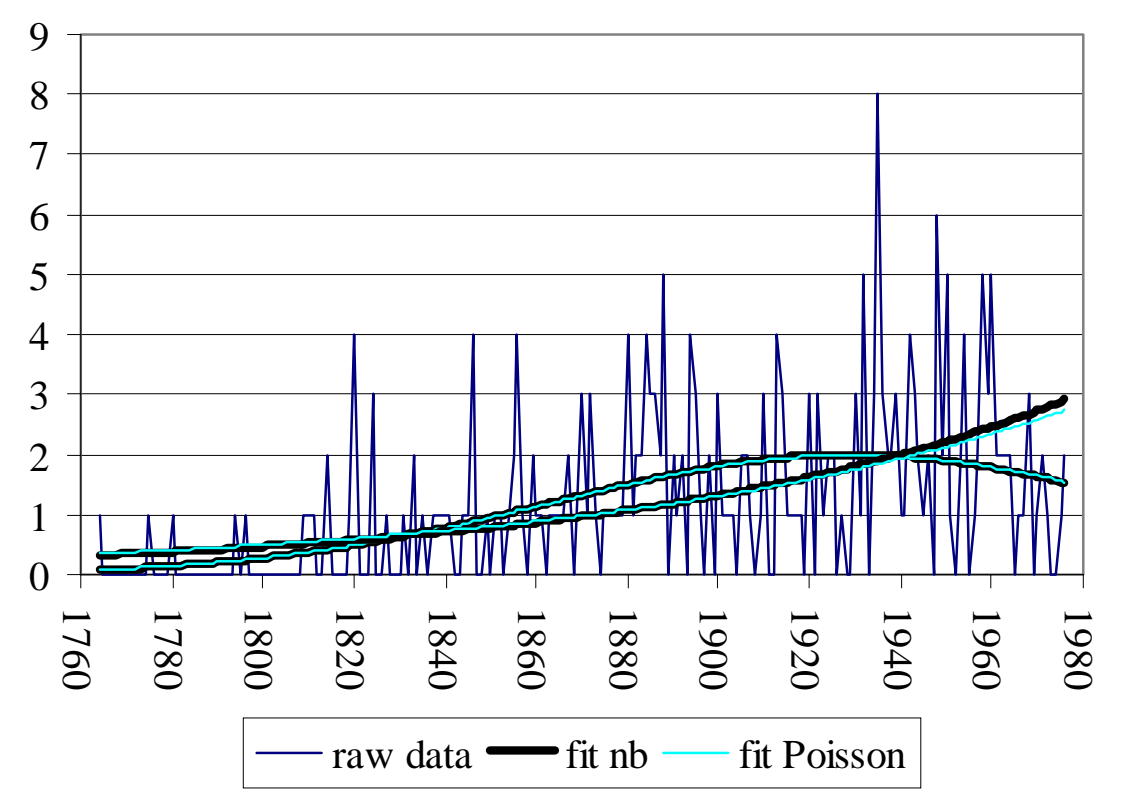

(b) Baker patents

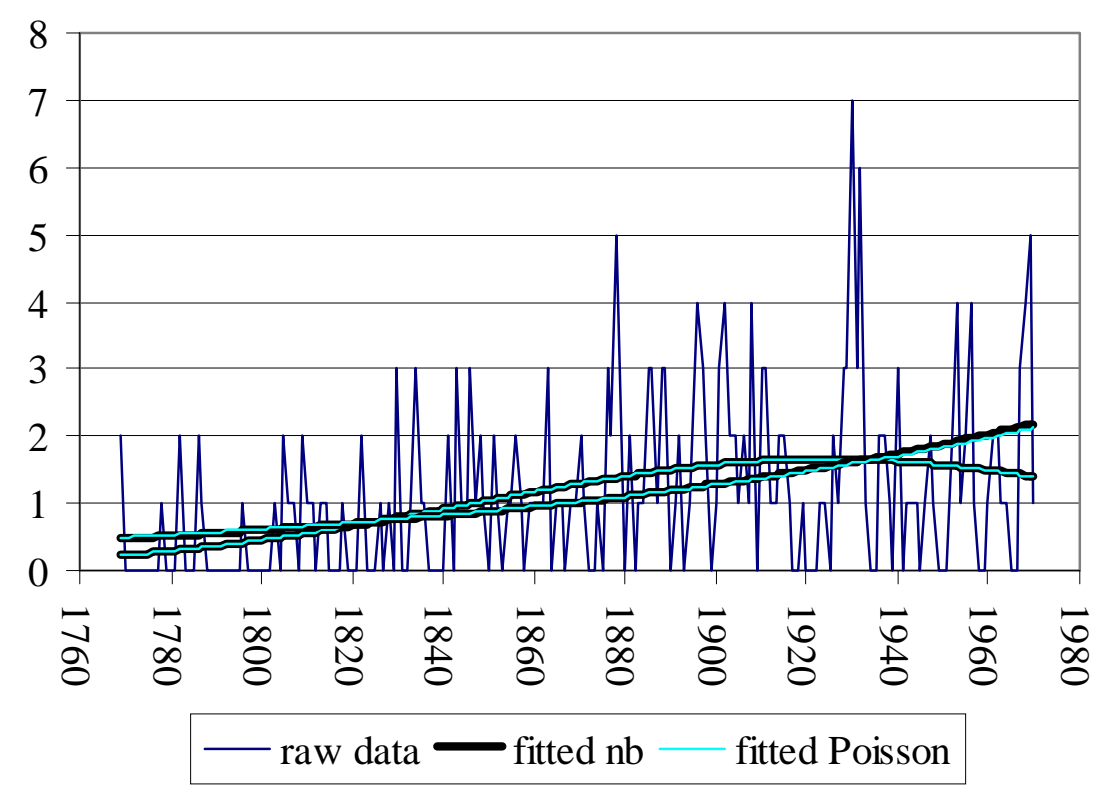

Figure 2. Raw data and fitted linear and quadratic trends (details of estimation are in Table 1) 
In order to get a first impression of the deviations from the long-run trend growth rate which bears on the three other hypotheses, an analysis of the autocorrelation of the residuals of the regressions was performed. To this end, the residuals were standardized by dividing them by the estimated standard deviation (square root of the variance). As explained in Annex I, in the case of a Poisson process, this implies dividing by the square root of the arrival rate itself (which varies over time when a trend is included). In the case of a negative binomial model, the variance is calculated as $\lambda(1+\alpha \lambda)$, where $\lambda$ is the estimated arrival rate, which again varies over time in the event of a time trend. We test for the null-hypothesis that all autocorrelations up to (and including) order $k(=1 . .20)$ are zero using two tests. The first is suggested by Cameron and Trivedi (p. 229), and "guards against incorrect standardization" of the residuals. The second is the standard Box-Ljung statistic. Both tests apply a statistic that is $\chi^{2}$ distributed with $\mathrm{k}$ degrees of freedom (the maximum order of the autocorrelation process).

The last column in Table 1 gives the significance level at which (if at all) we reject the nullhypothesis of no autocorrelation in the residuals. We used orders up to 20 to test for this. In the case of a time-homogenous process, there is clearly very significant autocorrelation, for both time series (patents and innovations) and both statistical models (Poison model and negative binomial). When time trends are included, this diminishes, although the extent to which this happens differs greatly between the two time series. With the innovation data, a linear time trend still leaves significant autocorrelation at the 5\% level; for the Baker patent time series at the $1 \%$ level for 3 of 4 cases. For higher order polynomial trends, however, autocorrelation vanishes completely in the case of the innovation data. For the patent data, the second and third order polynomial trends leave significant autocorrelation in the residuals at the $10 \%$ or $5 \%$ levels. These results suggest that for the Baker patent time series, the models in Table 1 leave at least some aspects of the longrun dynamics of the time series unexplained, and hence that there is scope for investigating the three other Schumpeterian hypotheses. We now proceed in two ways.

First, we estimate a set of autoregressive models specified in the way explained in Annex I. These models take, besides the variables already used, lagged values of the dependent variable itself as explanatory variables. One problem in estimating these models is to determine the exact order of the autoregressive process, i.e., to decide how many lagged terms to include. This is in fact common to all autoregressive models, and the approach most commonly found in the literature is an empirical procedure employing information criteria. These are simple statistics based on the log likelihood value of the models for different autoregressive orders. The simplest is the Aikake Information Criterion (AIC), which we will use here. The procedure is to find the minimum value of the AIC for a range of autoregressive orders, which in the present case we select as $0-20$. 
Table 2. Regression results, Poisson and Negative Binomial models, arrival rate function of time and lagged dependent variable

\begin{tabular}{|c|c|c|c|c|}
\hline \multirow[b]{2}{*}{ coefficient } & \multicolumn{2}{|c|}{ Innovations } & \multicolumn{2}{|r|}{ Baker patents } \\
\hline & (1) & (2) & (3) & (4) \\
\hline$c$ & $-2.7656(0.000)$ & $-2.6037(0.000)$ & $-1.6902(0.000)$ & $-3.3500(0.001)$ \\
\hline$\beta_{1}$ & $0.0424(0.000)$ & $0.0395(0.000)$ & $0.0271(0.000)$ & $0.0526(0.001)$ \\
\hline$\beta_{2}$ & $-0.1290^{\mathrm{b}}(0.000)$ & $-0.1207^{\mathrm{b}}(0.000)$ & $-0.8646^{c}(0.001)$ & $-0.1711^{\mathrm{b}}(0.003)$ \\
\hline$\alpha$ & $0.1762(0.078)$ & & & \\
\hline$\rho_{1}$ & $-0.0184(0.871)$ & $0.0431(0.675)$ & $0.2651(0.010)$ & $0.2342(0.056)$ \\
\hline$\rho_{2}$ & & $0.6907^{\mathrm{a}}(0.947)$ & $0.0933(0.302)$ & $0.0748(0.527)$ \\
\hline$\rho_{3}$ & & $-0.0809(0.422)$ & $-0.1776(0.056)$ & $-0.1914(0.122)$ \\
\hline$\rho_{4}$ & & $0.1680(0.065)$ & & $0.0622(0.617)$ \\
\hline$\rho_{5}$ & & $0.0516(0.578)$ & & $-0.1807(0.145)$ \\
\hline$\rho_{6}$ & & $-0.1155(0.234)$ & & $-0.0612(0.647)$ \\
\hline$\rho_{7}$ & & $-0.0417(0.692)$ & & $-0.0209(0.866)$ \\
\hline$\rho_{8}$ & & $0.0447(0.646)$ & & $0.0767(0.497)$ \\
\hline$\rho_{9}$ & & $-0.2083(0.040)$ & & $-0.1685(0.143)$ \\
\hline$\rho_{10}$ & & $0.2489(0.010)$ & & $-0.1302(0.323)$ \\
\hline$\rho_{11}$ & & $-0.2508^{\mathrm{a}}(0.983)$ & & $-0.1335(0.337)$ \\
\hline$\rho_{12}$ & & $-0.0263(0.801)$ & & $-0.1832(0.123)$ \\
\hline$\rho_{13}$ & & & & $0.1076(0.350)$ \\
\hline$\rho_{14}$ & & & & $-0.1912(0.125)$ \\
\hline$\rho_{15}$ & & & & $-0.2145^{\mathrm{a}}(0.987)$ \\
\hline$\rho_{16}$ & & & & $0.0867(0.480)$ \\
\hline$\rho_{17}$ & & & & $-0.1436(0.233)$ \\
\hline$\rho_{18}$ & & & & $-0.0891(0.479)$ \\
\hline$\rho_{10}$ & & & & $-0.0843(0.474)$ \\
\hline$\underline{\log 1}$ & -274.108 & -264.790 & -263.916 & -240.489 \\
\hline
\end{tabular}

Notes: $\beta_{1}$ and $\beta_{2}$ are the coefficients on the polynomials of time ( $1^{\text {st }}$ and $2^{\text {nd }}$ degree, respectively). $\alpha$ is the parameter for overdispersion in the negative binomial model. $\rho$ indicates the autoregressive terms, the subscript to $\rho$ the order of the autoregressive term. Estimated coefficients are equal to documented coefficients divided by the following factors (absence of a note indicates estimated coefficient is equal to documented coefficient): ${ }^{\mathrm{a}} 100,{ }^{\mathrm{b}} 1000,{ }^{\mathrm{c}} 10000$, ${ }^{\mathrm{d}} 1000000,{ }^{\mathrm{e}} 10000000$. Numbers between brackets are p-values associated with the $t$-statistics.

We estimated (and calculated the AIC for) a model with a quadratic exponential time trend plus autoregressive terms. Both a Poisson model and a negative binomial model were estimated for both time series and all autoregressive orders in the range $0-20$. For the innovation supersample, the Poisson model has minimum AIC at order 1, while the negative binomial model has minimum AIC at order 12. When the AIC is plotted against the autoregressive order, the Poisson model also has a local minimum that does not differ much in value from the global minimum at order 1 , at order 12 , while the negative binomial model has a local minimum (again not so much different from the global minimum) at order 1 . We therefore document the full set of results for the model at both orders 1 and 12. When the negative binomial term $\alpha$ is significant, we only document this model, while if it is not significant, we only document the Poisson model. 
For the Baker patent time series, the minimum value of the AIC was found at orders 19 (Poisson) and 12 (negative binomial). The Poisson model has a local minimum of the AIC at order 3 , which is also documented. In this case, the negative binomial term $\alpha$ is not significant for either the autoregressive order 19 or 3, which is why we document only pure Poisson models. The results for the autoregressive model are documented in Table 2. The autoregressive terms are indicated by the symbol $\rho$.

We note from the table that the significance of the time-parameters $\beta$ is largely unaffected, i.e., that the time trends estimated in Table 1 are robust against the inclusion of autoregressive terms. This does not hold for the negative binomial term $\alpha$. When autoregressive terms are included in the model, this term becomes insignificant in three of the four cases in Table 2 (and, in fact, in most of the undocumented autoregressive models that were run; these results are available on request). The general loss of significance of the negative binomial model points to the fact that the clustering effects that we have attributed above (in our Schumpeter Mark II.0 hypothesis and the discussion of Table 1) to overdispersion may in fact also (and statistically more satisfactorily) be captured by an autoregressive model.

Super 12

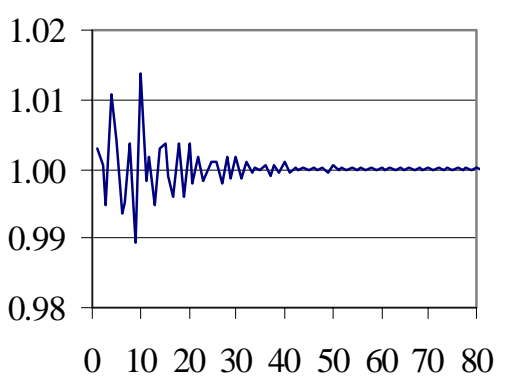

Baker 3

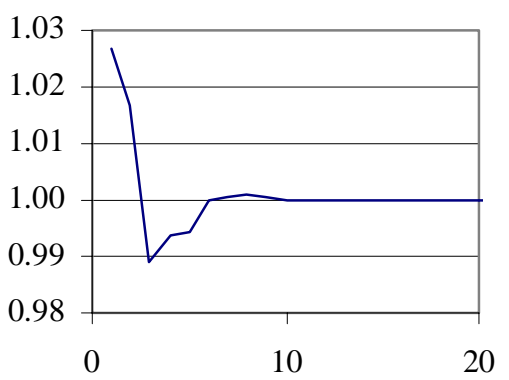

Baker 19

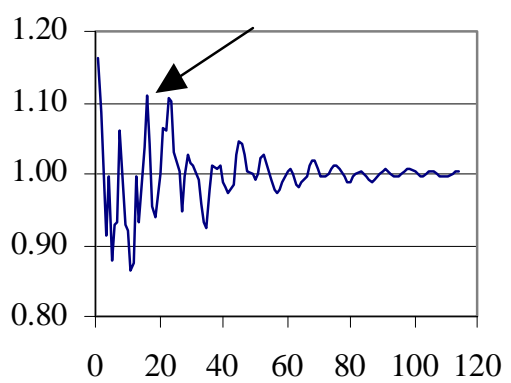

Figure 3. Impulse-response functions for the autoregressive processes in Table 2

This raises the question as to what pattern of clustering is implied by the estimated autoregressive structure, and whether this pattern is consistent with, for example, our Schumpeter Mark II.1 hypothesis. The answer to this question obviously depends on the value of the 
estimated $\rho$-parameters. As in a conventional autoregressive model, the values of these parameters have implications for the speed at which 'errors' leave their trace in the fitted time series. This speed can be visualized by plotting the impulse response function, which, because of the model we have specified in Section 3, must be a multiplicative function rather than the commonly used additive function (see, e.g., Hamilton, 1994, ch. 1).

Figure 3 shows the impulse response function for columns (2) - (4) in Table 2. The function for column (1) is almost completely flat and is therefore not documented. These graphs display the net multiplicative effect of a random innovation in period 0 on the arrival rate in the subsequent periods. For example, the figure for the Baker patent time series at autoregressive order 19 shows that the effect of one 'random extra' innovation in period 0 is to raise the arrival rate in period 19 by slightly more than $10 \%$ compared to a situation without such a random extra innovation (value of 1.1 at the peak is indicated by the arrow). Note that the fact that all three graphs converge to one implies that the effect of a random extra innovation ultimately dies out, i.e., that the process is (trend) stationary. Thus there will be no persistent long-term effect of a rise in the innovation rate

All three graphs show oscillatory behaviour following a 'random extra' innovation. This is caused by the negative autoregressive parameters ( $\rho$ ), and leads us to reject the Schumpeter Mark II. 1 hypothesis introduced above. This hypothesis argues that a random extra innovation leaves a slowly dying trace of (relatively) high innovation activity. Such a pattern would result if (most of) the estimated $\rho$ s had high positive values. With the large number of negative values for the autoregressive parameters we obtain in Table 2, the result is the highly irregular and randomlooking pattern observed in Figure 3. This is consistent to some extent with the Schumpeter Mark II.0 hypothesis of random clustering, but not with the Schumpeter Mark II.1 hypothesis.

This still leaves both Schumpeter Mark I hypotheses to be investigated. As a preliminary remark, note that if a strictly periodic pattern (possibly surrounding a trend of some form) existed in the data, one would expect the autoregressive specification to pick this up in some form. In other words, the irregular patterns observed in Figure 3 also have implications for the Schumpeter Mark I hypotheses, in particular, they cast doubt on them. To clarify this further, we employ an additional test to reach a final verdict on Schumpeter Mark I.

This test does not involve data on economic variables, as called for in the Mark I.1 hypothesis. Instead, we investigate the residuals from the regressions in Table 1 to see if any strictly periodic movements can be detected. To this end, we perform spectral analysis on the standardized residuals (defined above). If the Schumpeter Mark I hypotheses are valid, one would expect clear peaks in the spectral density plot for these residuals, as a result of strictly periodic movements around the estimated trend arrival rate.

Figure 4 displays the spectral density plots for residuals from the Poisson and negative binomial regressions in Table 1. Although there clearly are some peaks in the plots, these are consistent with white-noise data. The overall impression is one of a relatively flat spectrum, which indicates the absence of clear periodic components in the residuals. This holds especially for the 
supersample innovation time series, and to a somewhat lesser extent for the Baker patent time series.

\section{Supersample}

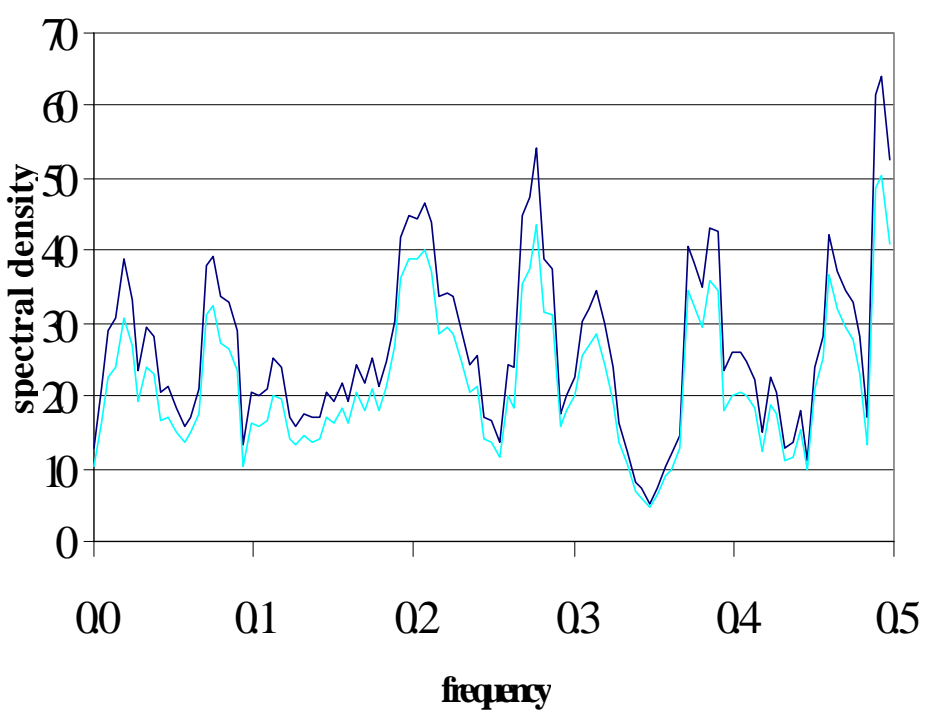

- Paisson - Negdin

\section{Bakerpatents}

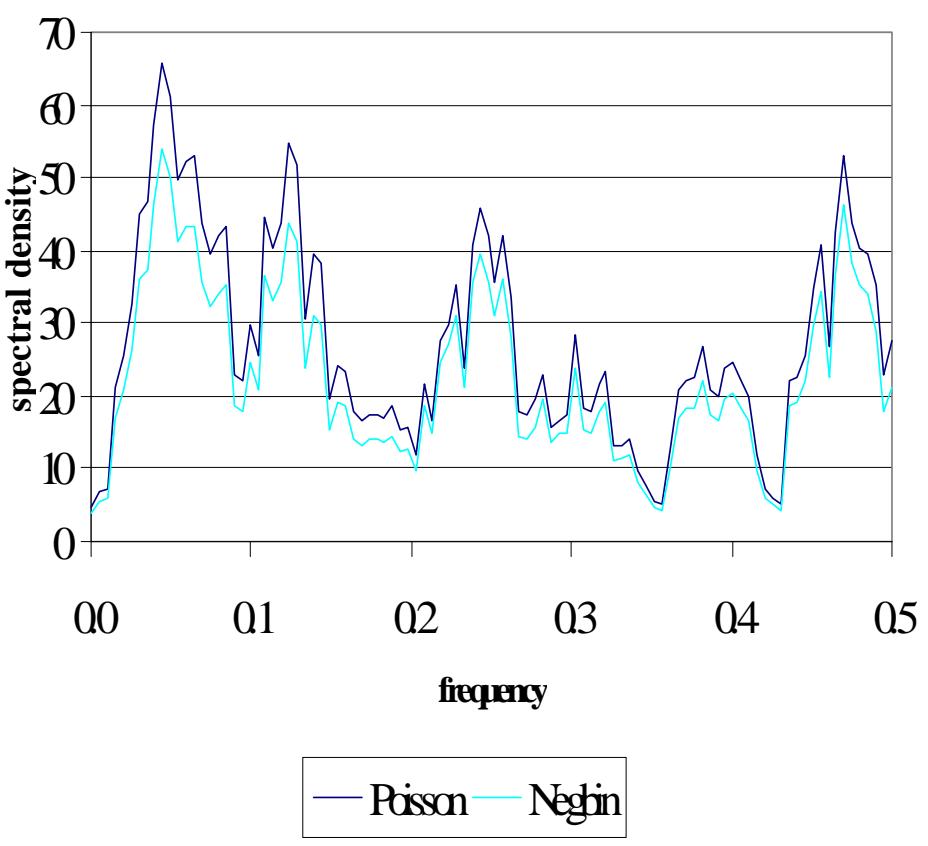

Figure 4. Spectral density plots for the residuals of the quadratic trend regressions in Table 1. 
We thus conclude that the evidence in favour of strictly periodic movements around the (exponential) quadratic trend in the arrival rate is weak. The finding that is closest to our Schumpeter Mark I hypotheses is the 'weak' peak at a cycle length of 20 years in the Baker patent time series.

\section{Summary and conclusions}

This paper pursues a suggestion made by Silverberg and Lehnert (1993) in their discussion of the empirical evidence on the 'Schumpeterian hypothesis' that basic innovations tend to cluster. They proposed, in order to overcome the methodological shortcoming of previous work, modeling and estimating a stochastic Poisson process describing the occurrence of basic innovations. We formulate four alternative hypotheses bearing on the Schumpeterian clustering hypothesis that are amenable to statistical testing. We then estimated a model of the trend in the arrival rate of basic innovations, and found that a quadratic exponential trend fits the data best (compared to a linear or third-degree trend). Investigating the residuals of this regression for periodic cycles around the trend, we found essentially no evidence in favour of such strong periodic clustering.

A weaker version of the clustering theory interprets clusters as themselves randomly distributed. Evidence for this interpretation is presented in the form of estimates of the negative binomial parameter, which is found to be significantly different from zero.

A different version of random clustering occurs when random events tend to 'persist' in time, for example due to an autoregressive process. We have estimated autoregressive Poisson and negative binomial models (again based on a quadratic exponential trend), and found that these models may indeed improve the fit. However, by plotting the impulse response functions, we showed that innovation impulses do not lead to long periods of above-normal innovative activity. Rather, such impulses die out in an oscillatory way, and leave a rather irregular and randomlooking trace. We interpret this as evidence against a knock-on effect being the source of clustering.

We are thus left with the conclusion that the only form of clustering of basic innovations that is consistent with the data is 'random clustering' superimposed on a second-degree trend. Basic innovations, while they arrive in clusters, do not engender higher rates of basic innovative activity (although they may initiate periods of higher incremental innovation not picked up in our data), nor are these clusters in any way periodic. Thus even if we have just come through a period of exceptionally high innovation in the 1990s (the purported 'new economy'), this is no guarantee that innovation rates will remain at historically high levels in the future. To what extent these rates are influenced by the macroeconomic context is a subject we hope to study further. 


\section{References}

Baker, R. (1976). New and improved: inventors and inventions that have changed the modern world. London, British Museum Publications.

Cameron, A.C. and P.K. Trivedi. (1998). Regression Analysis of Count Data. Econometric Society Monographs. Vol. 30, Cambridge: Cambridge University Press.

Cincera, M. (1997). "Patents, R\&D and technological spillovers at the firm level: some evidence from econometric count models for panel data." Journal of Applied Econometrics 12: 265280.

Crepon, B. and E. Duguet (1997a). "Estimating the innovation function from patent numbers: GMM on count panel data." Journal of Applied Econometrics 12: 243-263.

Crepon, B. and E. Duguet (1997b). "Research and development, competition and innovation pseudo-maximum likelihood and simulated maximum likelihood methods applied to count data models with heterogeneity." Journal of Econometrics 79: 355-378.

Freeman, C., J. Clark, and L. Soete (1982). Unemployment and Technical Innovation. London, Pinter.

Freeman, C. and C. Perez (1988), "Structural Crises of Adjustment, Business Cycles and Investment Behaviour." in G. Dosi, C. Freeman, R. Nelson, G. Silverberg and L. Soete (eds), Technical Change and Economic Theory, London, Pinter.

Freeman, C. and L. Soete (1997). The Economics of Industrial Innovation. 3rd Edition. London and Washington, Pinter.

Gordon, R. J. (2000), "Does the 'New Economy' Measure up to the Great Inventions of the Past?", Journal of Economic Perspectives, 14: 49-74.

Greene, W. (1995). Econometric Analysis, 3rd ed. New Jersey, Prentice Hall.

Hamilton, J.D. (1994). Time Series Analysis. Princeton: Princeton University Press.

Hausman, J., B. H. Hall and Z. Griliches (1984). "Econometric Models for Count Data with an Application to the Patents-R\&D Relationship." Econometrica 52: 909-938.

Haustein, H.-D. and E. Neuwirth (1982). "Long Waves in World Industrial Production, Energy Consumption, Innovations, Inventions, and Patents and Their Identification by Spectral Analysis." Technological Forecasting and Social Change 22: 53-89.

Jewkes, J., Sawers, D. and Stillerman, R. (1958), The Sources of Invention, London, Macmillan. Kleinknecht, A. (1981). "Observations on the Schumpeterian Swarming of Innovations." Futures 13: 293-307.

Kleinknecht, A. (1987). Innovation Patterns in Crisis and Prosperity. Schumpeter's Long Cycle Reconsidered. London, Macmillan.

Kleinknecht, A. (1990). "Are there Schumpeterian Waves of Innovations?" Cambridge Journal of Economics 14: 81-92.

Kondratieff, N. D. (1926/1935), "Die langen Wellen der Konjunktur." Archiv für Sozialwissenschaft und Sozialpolitik, 56: 573-609, English translation: "The Long Waves in 
Economic Life." The Review of Economic Statistics, 17: 105-115.

Kuznets, S. (1940). "Schumpeter's Business Cycles.” American Economic Review 30: 257-271.

Mensch, G. (1975/1979). Das technologische Patt, Frankfurt, Umschau. English translation: Stalemate in Technology. Innovations Overcome Depression. Cambridge, Ballinger.

Sahal, D. (1974). "Generalized Poisson and Related Models of Technological Innovation." Technological Forecasting and Social Change 6: 403-436.

Schumpeter, J. A. (1939). Business Cycles: A theoretical, historical and statistical analysis of the capitalist process. New York, McGraw-Hill (page numbers quoted in the text refer to the abridged version reprinted in 1989 by Porcupine Press, Philadelphia).

Silverberg, G. and D. Lehnert (1993). "Long Waves and 'Evolutionary Chaos' in a Simple Schumpeterian Model of Embodied technical Change", Structural Change and Economic Dynamics, 4: 9-37.

Solomou, S. (1986). "Innovation clusters and Kondratieff long waves in economic growth." Cambridge Journal of Economics 10, pp. 101-112.

Ten Raa, T. And E.N. Wolff (2000). "Engines of Growth in the U.S. Economy", Structural Change and Economic Dynamics, 11: 433-472.

Van Duijn, J. J. (1983). The Long Wave in Economic Life. London, Allen \& Unwin. 


\section{Annex I - Poisson regression}

The starting point for all statistical analysis in this paper is the (time-homogeneous) Poisson process, which makes the simplifying assumption that the probability of occurrence of an innovation within a given interval of time is independent of previous innovations and independent of time. The probability of $y$ innovations during an interval of time $T$ is given by

$$
\operatorname{Prob}(y)=\frac{e^{-\lambda T}(\lambda T)^{y}}{y !}
$$

where $y \varepsilon \mathbb{N}$, and $\lambda$ is a parameter, often referred to as the arrival rate of the Poisson process. Note that $\lambda$ is not necessarily an integer number. It is easily shown that the expected number of events per unit time is $\lambda$, which also happens to be the variance of the distribution. Note that time series generated from a time-homogeneous Poisson process will not display a completely uniform pattern of occurrences of the random event. In other words, to the naive eye some clustering will characterize even this simplest point process.

The parameter $\lambda$ may also be specified endogenously, for example as $\ln \lambda=\boldsymbol{\beta}$ ' $\mathbf{x}$, where $\mathbf{x}$ is a vector of independent variables, and $\boldsymbol{\beta}$ is a parameter vector. Other specifications for $\lambda$ are possible, but the example above is often used because it is convenient for estimation purposes (using $\ln \lambda$ as the independent variable ensures non-negative arrival rates). In this case, the parameter vector $\boldsymbol{\beta}$ can be interpreted as a vector of elasticities of the arrival rate with respect to the independent variables. Such an approach allows to test the assumption that the Poisson process is time-homogeneous by setting up the null hypothesis that all elements of $\boldsymbol{\beta}$, including one corresponding to time itself, are equal to zero.

One problem with the Poisson model is its peculiarity that the mean and variance of the distribution are equal. Empirical data often show a larger variance than mean for the dependent variable, a phenomenon termed 'overdispersion'. Hausman, Hall and Griliches (1984) for example observed overdispersion in their firm-level patent database. A model that can account for overdispersion may be obtained by adding an unobserved random effect to the mean of the Poisson distribution (Hausman, Hall and Griliches, 1984). This leads to a modified probability distribution of the type:

$$
\operatorname{Prob}(Y=y \mid u)=\frac{e^{-\lambda u}(\lambda u)^{y}}{y !}
$$

where $u$ is a random variable for which some distribution must be assumed (see Greene, 1995, p. 939). The variable $u$ may, for example, reflect random noise, or cross-sectional heterogeneity (when the model is estimated in the cross-sectional dimension). Assuming that $u$ is gamma distributed, one obtains the following unconditional distribution (Cameron and Trivedi, 1998, p. 
71):

$$
\operatorname{Prob}(Y=y \mid \mathbf{x})=\frac{\Gamma\left(\alpha^{-1}+y\right)}{\Gamma(y+1) \Gamma\left(\alpha^{-1}\right)} r^{y}(1-r)^{\alpha^{-1}}, \quad \text { where } r=\frac{\lambda}{\lambda+\alpha^{-1}}
$$

This distribution is known as the negative binomial distribution and has mean $\lambda$ and variance $\lambda(1+\alpha \lambda)$ for $\alpha>0$. When $\alpha$ approaches 0 , the model reduces to a standard Poisson model, and the variance becomes equal to $\lambda$ again. The negative binomial model can also be estimated using a maximum likelihood method. A test of the Poisson against the negative binomial distribution can be implemented by means of a Likelihood Ratio test, Wald test or $t$-test (Green, 1995) of the null hypothesis $\alpha=0$.

In the context of time series and the hypothesis of clustering of events (innovations) in specific time periods, the correlation structure of the residuals becomes of interest. Cameron and Trivedi (1998) suggest investigating the standardized residual $z_{t}=\left(y_{t}-m_{t}\right) / \sqrt{ } \sigma_{t}$, where $y_{t}$ is the observed (integer) value, $m_{t}$ is the sample mean value and $\sigma_{t}$ is the sample variance. When a Poisson model is fitted, $m_{t}=\sigma_{t}$ is equal to the estimated arrival rate. Cameron and Trivedi (1998) then suggest applying either the Box-Pierce portmanteau, the Box-Ljung statistic (which has better small sample properties) or a slightly modified statistic that guards against incorrect standardization, to test for the null-hypothesis that all autocorrelations of the residuals up to lag $k$ are zero.

In case such a null-hypothesis is rejected, various ways are suggested (Cameron and Trivedi, 1998, Section 7.5) of specifying a model to deal with the autocorrelated residuals. The method closest to our original Poisson regression approach is to estimate an autoregressive model, i.e., to include lagged values of the dependent variable in the regression as independent variables. The simplest model is called exponential feedback, and assumes $\ln \lambda_{t}=\beta \mathbf{x}_{t}+\rho y_{t-1}$. This, however, implies explosive behaviour for $\rho>0$. In order to rule out this undesirable property, Cameron and Trivedi suggest using $\lambda_{t}=\exp \left(\beta^{\prime} \mathbf{x}_{t}\right) \sum_{k}\left(y_{t-k}{ }_{t}\right)_{k}{ }_{k}$, where $y^{*}$ is a transformation of $y$ to ensure positive values, $y^{*}=\max (1 / 2, y)$, or $y^{*}=y+1 / 2$. 


\section{Annex II - Data on basic innovations}

Table A1. The supersample of basic innovations

$\begin{array}{lll}\text { Item Innovation } & \text { Yea } \\ \text { number }\end{array}$

\begin{tabular}{lll}
\hline 89 & Spinning machine & 1764 \\
90 & Steam engine & 1775 \\
91 & Automatic band loom & 1780 \\
92 & Sliding carriage & 1794 \\
81 & Blast furnace & 1796 \\
48 & Steam ship & 1809 \\
95 & Whitney's method & 1810
\end{tabular}

80 Crucible steel 1811

$183 \quad$ Street lighting (gas) 1814

$184 \quad$ Mechanical printing press 1814

$78 \quad$ Lead chamber process 1819

77 Quinine 1820

$98 \quad$ Isolated conduction $\quad 1820$

99 Rolled wire 1820

100 Cartwright's loom 1820

3 Steam locomotive 1824

61 Cement 1824

$66 \quad$ Puddling furnace 1824

$101 \quad$ Pharma fabrication $\quad 1827$

102 Calciumchlorate 1831

79 Telegraphy 1833

103 Urban gas 1833

$104 \quad$ Rolled rails 1835

$87 \quad$ Electric motor 1837

67 Photography 1838

9 Bicycle 1839

$88 \quad$ Vulcanized rubber 1840

$7 \quad$ Arc lamp 1841

105 Jacquard loom 1844

106 Lathe 1845

107 Inductor 1846

$108 \quad$ Electrodynamic measuring 1846

185 Rotary press 1846

186 Anaestetics 1846

187 Steel (puddling process) 1849

188 Sewing machine 1851

109 Plaster of paris 1852

14 Aluminium 1854

40 Safety match 1855

189 Bunsen burner 1855

36 Refined steel/Bessemer steel 1856

84 Steel pen / Fountain pen 1856 


\begin{tabular}{|c|c|c|}
\hline 110 & Tare colours industry & 1856 \\
\hline 111 & Baking powder & 1856 \\
\hline 190 & Elevator & 1857 \\
\hline 76 & Lead battery & 1859 \\
\hline 191 & Drilling for oil & 1859 \\
\hline 54 & Internal combustion engine & 1860 \\
\hline 39 & Soda works & 1861 \\
\hline 19 & Anilin dyes & 1863 \\
\hline 192 & Siemens-Martin steel & 1864 \\
\hline 112 & Paper from wood & 1865 \\
\hline 4 & Deep sea cable & 1866 \\
\hline 50 & Dynamite & 1867 \\
\hline 75 & Dynamo & 1867 \\
\hline 113 & Commutator & 1869 \\
\hline 60 & Typewriter & 1870 \\
\hline 193 & Celluloid & 1870 \\
\hline 194 & Combine harvester & 1870 \\
\hline 85 & Margarine & 1871 \\
\hline 6 & Thomas steel & 1872 \\
\hline 46 & Reinforced concrete & 1872 \\
\hline 114 & Drum rotor & 1872 \\
\hline 115 & Preservatives & 1873 \\
\hline 51 & Sulphuric acid & 1875 \\
\hline 195 & Four-stroke engine & 1876 \\
\hline 5 & Telephone & 1877 \\
\hline 116 & Nickel & 1878 \\
\hline 53 & Electric Railway & 1879 \\
\hline 12 & Incandescent lamp & 1880 \\
\hline 47 & Water turbine & 1880 \\
\hline 117 & Jodoforme & 1880 \\
\hline 196 & Half-tone process & 1880 \\
\hline 197 & Electric power station & 1881 \\
\hline 118 & Veronal & 1882 \\
\hline 119 & Cable & 1882 \\
\hline 120 & Antipyrin & 1883 \\
\hline 121 & Coals whisks & 1883 \\
\hline 10 & Steam turbine & 1884 \\
\hline 122 & Chloroforme & 1884 \\
\hline 198 & Punched card & 1884 \\
\hline 199 & Cash register & 1884 \\
\hline 38 & Syntethic fertilizers & 1885 \\
\hline 52 & Transformer & 1885 \\
\hline 123 & Synthetic alcaloids & 1885 \\
\hline 124 & Magnesium & 1886 \\
\hline 125 & Electric welding & 1886 \\
\hline 200 & Linotype & 1886 \\
\hline
\end{tabular}


126 Electrolyse 1887

$28 \quad$ Motor car 1888

59 Pneumatic tyre 1888

$127 \quad$ Electric counter 1888

$201 \quad$ Portable camera 1888

$202 \quad$ Alternating-current generator 1888

86 Man-made fibres 1890

128 Chemical fibres 1890

129 Melting by induction 1891

83 Acetylene welding 1892

130 Accounting machine 1892

41 Cinematography 1894

$131 \quad$ Antitoxines 1894

203 Motor cycle 1894

204 Monotype 1894

$8 \quad$ Diesel engine 1895

132 Drilling machine for mining 1895

$205 \quad$ Electric automobile 1895

206 X-rays 1896

37 Aspirin 1898

133 Arc welding 1898

134 Air ship 1900

135 Synthesis of indigo 1900

207 Submarine 1900

136 Holing machine 1901

137 Electric steel making $\quad 1902$

208 Safety razor 1903

$209 \quad$ Viscose rayon 1905

$210 \quad$ Vacuum cleaner 1905

138 Acetylen 1906

211 Chemical accelerator for rubber 1906

$\begin{array}{ll}\text { vulcanization } & \\ \text { Electric washing machine } & 1907\end{array}$

$\begin{array}{lll}212 & \text { Electric washing machine } & 1907 \\ 15 & \text { Gyro compass } & 1909\end{array}$

2 Airplane 1910

69 Bakelite (Phenol plastics) 1910

139 High voltage isolation 1910

$65 \quad$ Vacuum tube 1913

$71 \quad$ Assembly line 1913

213 Thermal cracking 1913

214 Domestic refrigerator 1913

140 Ammonia synthesis 1914

141 Tractor 1914

$215 \quad$ Stainless steel 1914

142 Tank 1915

32 Synthetic rubber 1916 


\begin{tabular}{|c|c|c|}
\hline 42 & Cellophane & 1917 \\
\hline 1 & Zip fastener & 1918 \\
\hline 29 & AM Radio & 1920 \\
\hline 216 & Acetate rayon & 1920 \\
\hline 217 & Continuous thermal cracking & 1920 \\
\hline 26 & Synthetic detergents & 1922 \\
\hline 57 & Insuline & 1922 \\
\hline 143 & Synthesis of methanol & 1922 \\
\hline 35 & Continuous rolling & 1923 \\
\hline 218 & Dynamic loudspeaker & 1924 \\
\hline 219 & Leica camera & 1924 \\
\hline 144 & Deep frozen food & 1925 \\
\hline 220 & Electric record player & 1925 \\
\hline 145 & Coal hydrogenation & 1927 \\
\hline 17 & Power steering & 1930 \\
\hline 221 & Polystyrene & 1930 \\
\hline 222 & Rapid freezing & 1930 \\
\hline 223 & Freon refrigerants & 1931 \\
\hline 34 & Crease-resistent fabrics & 1932 \\
\hline 224 & Gas turbine & 1932 \\
\hline 225 & Polyvinylchloride & 1932 \\
\hline 226 & Antimalaria drugs & 1932 \\
\hline 227 & Sulfa drugs & 1932 \\
\hline 56 & Fluor lamp & 1934 \\
\hline 146 & Diesel locomotive & 1934 \\
\hline 147 & Fischer-Tropsch procedure & 1934 \\
\hline 11 & Radar & 1935 \\
\hline 13 & Ballpoint pen & 1935 \\
\hline 30 & Rockets/guided missiles & 1935 \\
\hline 31 & Plexiglas & 1935 \\
\hline 62 & Magnetophone & 1935 \\
\hline 70 & Catalytic cracking & 1935 \\
\hline 82 & Colour photo & 1935 \\
\hline 148 & Gasoline & 1935 \\
\hline 16 & Television & 1936 \\
\hline 149 & Photoelectric cell & 1936 \\
\hline 228 & FM radio & 1936 \\
\hline 150 & Vitamins & 1937 \\
\hline 229 & Electron microscope & 1937 \\
\hline 20 & Helicopter & 1938 \\
\hline 230 & Nylon & 1938 \\
\hline 21 & Polethylene & 1939 \\
\hline 55 & Automatic gears & 1939 \\
\hline 151 & Hydraulic gear & 1939 \\
\hline 27 & Antibiotics (penicilline) & 1940 \\
\hline 152 & Cotton picker & 1941 \\
\hline
\end{tabular}




\begin{tabular}{|c|c|c|}
\hline 43 & Jet engine/plane & 1942 \\
\hline 45 & DDT & 1942 \\
\hline 153 & Heavy water & 1942 \\
\hline 231 & Continuous catalytic cracking & 1942 \\
\hline 24 & Silcones & 1943 \\
\hline 232 & Aerosol spray & 1943 \\
\hline 233 & High-energy accelerators & 1943 \\
\hline 44 & Streptomycine & 1944 \\
\hline 154 & Titanreduction & 1944 \\
\hline 22 & Sulzer loom & 1945 \\
\hline 68 & Oxygen steelmaking & 1946 \\
\hline 234 & Phototype & 1946 \\
\hline 49 & Numerically controlled machine tools & 1948 \\
\hline 58 & Continuous steel making & 1948 \\
\hline 235 & Orlon & 1948 \\
\hline 236 & Cortisone & 1948 \\
\hline 237 & Long-playing record & 1948 \\
\hline 238 & Polaroid land camera & 1948 \\
\hline 155 & Thonet furniture & 1949 \\
\hline 156 & Polyester & 1949 \\
\hline 18 & Computer & 1950 \\
\hline 23 & Transistor & 1950 \\
\hline 25 & Xerography & 1950 \\
\hline 239 & Terylene & 1950 \\
\hline 240 & Radial tyre & 1950 \\
\hline 157 & Double-floor railway & 1951 \\
\hline 158 & Cinerama & 1953 \\
\hline 241 & Colour television & 1953 \\
\hline 33 & Nuclear energy & 1954 \\
\hline 242 & Gas chromatograph & 1954 \\
\hline 243 & Remote control & 1954 \\
\hline 244 & Silicon transistor & 1954 \\
\hline 159 & Air compressed building & 1956 \\
\hline 160 & Atomic ice breaker & 1957 \\
\hline 161 & Space travel & 1957 \\
\hline 162 & Stitching bond & 1958 \\
\hline 163 & Holography & 1958 \\
\hline 164 & Transistor radio & 1958 \\
\hline 165 & Diffusion process & 1958 \\
\hline 245 & Fuel cell & 1958 \\
\hline 166 & Quartz clocks & 1959 \\
\hline 246 & Polyacetates & 1959 \\
\hline 247 & Float glas & 1959 \\
\hline 167 & Maser & 1960 \\
\hline 168 & Micro modules & 1960 \\
\hline 248 & Polycarbonates & 1960 \\
\hline
\end{tabular}




\begin{tabular}{|c|c|c|}
\hline 249 & Contraceptive pill & 1960 \\
\hline 250 & Hovercraft & 1960 \\
\hline 64 & Integrated circuit & 1961 \\
\hline 169 & Planar process & 1961 \\
\hline 73 & Laser & 1962 \\
\hline 251 & Communication satellite & 1962 \\
\hline 170 & Implementation of ions & 1963 \\
\hline 171 & Epitaxy & 1963 \\
\hline 172 & Synthetic leather & 1964 \\
\hline 173 & Transistor laser & 1964 \\
\hline 174 & Optoelectronic diodes & 1966 \\
\hline 252 & Wankel-motor & 1967 \\
\hline 74 & Video & 1968 \\
\hline 175 & Light emitting fluor display & 1968 \\
\hline 176 & Minicomputers & 1968 \\
\hline 177 & Quartz watches & 1970 \\
\hline 63 & Microprocessor & 1971 \\
\hline 178 & Electronic calculator & 1971 \\
\hline 179 & Light-tunnel technology & 1972 \\
\hline 180 & 16-bit microprocessor & 1975 \\
\hline 181 & 16384 bit RAM & 1976 \\
\hline 182 & Microcomputer & 1976 \\
\hline
\end{tabular}

Note: items 1-88 occur in both databases, items 89-182 occur only in Haustein and Neuwirth data, items 183-252 occur only in Van Duijn data.

Table A2. Innovations in the Haustein and Neuwirth time series that were matched to innovations in the Van Duijn time series

\begin{tabular}{lll} 
Innovation & Year & To which item in merged series? \\
\hline Blast furnace & 1796 & to 81 \\
Steamer & 1809 & to 48 \\
Crucible cast steel & 1811 & to 80 \\
Lead-chamber process & 1819 & to 78 \\
Chinin fabrication & 1820 & to 77 \\
Locomotive & 1824 & to 3 \\
Puddling furnace & 1824 & to 66 \\
Telegraphy & 1833 & to 79 \\
Photography & 1838 & to 67 \\
Bicycle (pedal) & 1839 & to 9 \\
Cement & 1844 & to 61 \\
Arc lamp & 1844 & to 7 \\
Generator of current & 1849 & to 87 \\
Hard rubber & 1852 & to 88 \\
Aluminium & 1854 & to 14 \\
Refined steel & 1856 & to 36 \\
Steel pen & 1856 & to 84 \\
Lead accumulator & 1859 & to 76
\end{tabular}




\begin{tabular}{|c|c|c|}
\hline Soda works & 1861 & to 39 \\
\hline Production of analin & 1863 & to 19 \\
\hline Deep sea cable & 1866 & to 4 \\
\hline Safety matches & 1866 & to 40 \\
\hline Dynamite & 1867 & to 50 \\
\hline Dynamo & 1867 & to 75 \\
\hline Thomas steel & 1872 & to 6 \\
\hline Typewriter & 1873 & to 60 \\
\hline Sulphuric acid production & 1875 & to 51 \\
\hline Telephone & 1878 & to 5 \\
\hline Electric locomotive & 1879 & to 53 \\
\hline Incandescent lamp & 1880 & to 12 \\
\hline Cooking fat & 1882 & to 85 \\
\hline Electricity & 1882 & to 87 \\
\hline Electric heating & 1882 & to 87 \\
\hline Long distance conduction & 1882 & to 87 \\
\hline Synthetic fertilizers & 1885 & to 38 \\
\hline Transformers & 1885 & to 52 \\
\hline Combustion engine & 1886 & to 54 \\
\hline Phonograph & 1887 & to 72 \\
\hline Tyres with air compression & 1888 & to 59 \\
\hline Water turbine & 1890 & to 47 \\
\hline Welding by acetylene & 1892 & to 83 \\
\hline Steam turbine & 1895 & to 10 \\
\hline Automobile & 1895 & to 28 \\
\hline Cinematography & 1895 & to 41 \\
\hline Electric railway & 1895 & to 53 \\
\hline Diesel engine & 1897 & to 8 \\
\hline Aspirin & 1898 & to 37 \\
\hline Steel concrete & 1902 & to 46 \\
\hline Gyro compass & 1909 & to 15 \\
\hline Pheno plastics & 1910 & to 69 \\
\hline Airplane & 1911 & to 2 \\
\hline Conveyor belt production & 1913 & to 71 \\
\hline Synthetic rubber & 1916 & to 32 \\
\hline Electronic tubes & 1920 & to 65 \\
\hline Detergents/synthetic & 1922 & to 26 \\
\hline Radio & 1922 & to 29 \\
\hline Insuline & 1922 & to 57 \\
\hline Zip fastener & 1923 & to 1 \\
\hline Continuous rolling & 1923 & to 35 \\
\hline Cellophane & 1926 & to 42 \\
\hline Power steering & 1930 & to 17 \\
\hline Crease-resistant fabrics & 1932 & to 34 \\
\hline Fluorescent lamp & 1934 & to 56 \\
\hline Ball-point pen & 1935 & to 13 \\
\hline
\end{tabular}




\begin{tabular}{lll} 
Rockets & 1935 & to 30 \\
Plexiglass & 1935 & to 31 \\
Magnetophone & 1935 & to 62 \\
Catalytic cracking & 1935 & to 70 \\
Colour film & 1935 & to 82 \\
TV & 1936 & to 16 \\
Radar & 1939 & to 11 \\
Helicopter & 1939 & to 20 \\
Automatic gears & 1939 & to 55 \\
Synthetic fibres & 1939 & to 86 \\
Antibiotics & 1940 & to 27 \\
DDT & 1942 & to 45 \\
Jet engine & 1943 & to 43 \\
Streptomycine & 1944 & to 44 \\
Sulzer loom & 1945 & to 22 \\
Silicons & 1946 & to 24 \\
Oxygen-process & 1946 & to 68 \\
NC machines & 1948 & to 49 \\
Continuous steelmaking & 1948 & to 58 \\
Computer & 1950 & to 18 \\
Transistor & 1950 & to 23 \\
Xerographie & 1950 & to 50 \\
Polyethylene & 1953 & to 21 \\
Nuclear power station & 1954 & to 33 \\
Integrated circuits & 1961 & to 64 \\
Laser & 1962 & to 73 \\
Video-tape recorder & 1968 & to 74 \\
Microprocessor & 1971 & to 63 \\
\hline
\end{tabular}

Table A3. Innovations in the Van Duijn time series that were matched to innovations in the Haustein and Neuwirth time series

Innovation

Crucible steel

Sulphuric acid (lead chamber process)

Quinine

Portland cement

Coke blast furnace

Steam locomotive

Puddling furnace

Electric motor

Steamship (Atlantic crossing)

Photography

Electric telegraph

Vulcanized rubber

Arc lamp

Safety match

Bessemer steel
Year To which item in merged series?

$\begin{array}{ll}1811 & \text { to } 80 \\ 1819 & \text { to } 78 \\ 1820 & \text { to } 77 \\ 1824 & \text { to } 61 \\ 1829 & \text { to } 81 \\ 1830 & \text { to } 3 \\ 1832 & \text { to } 66 \\ 1837 & \text { to } 87 \\ 1838 & \text { to } 48 \\ 1839 & \text { to } 67 \\ 1839 & \text { to } 79 \\ 1840 & \text { to } 88 \\ 1841 & \text { to } 7 \\ 1855 & \text { to } 40 \\ 1856 & \text { to } 36\end{array}$


Lead battery

Internal combustion engine

Sodium carbonate

Aniline dyes

Atlantic telegraph cable

Dynamite

Dynamo

Typewriter

Margarine

Reinforced concrete

Sulphuric acid

Telephone

Electric railway

Thomas oven

Incandescent lamp

Water turbine

Steam turbine

Fountain pen

Transformer

Bicycle

Aluminium

Motor car

Cylindrical record player

Pneumatic tyre

Mechanical record player

Rayon (nitro-cellulose pr.)

Motion picture film

Diesel engine

Rayon (cuprammonium pr.)

Aspririn

Oxy-acetylene welding

Airplane

Bakelite

Gyro compass

Synthetic fertilizer (nitrogen)

Vacuum tube

Assembly line

Cellophane

Zip fastener

AM radio

Continuous hot strip rolling

Insulin

Synthetic detergents

Synthetic rubber

Crease-resisting fabrics

Radar

\begin{tabular}{|c|c|}
\hline 1859 & to 76 \\
\hline 1860 & to 54 \\
\hline 1861 & to 39 \\
\hline 1865 & to 19 \\
\hline 1866 & to 4 \\
\hline 1867 & to 50 \\
\hline 1867 & to 75 \\
\hline 1870 & to 60 \\
\hline 1871 & to 85 \\
\hline 1872 & to 46 \\
\hline 1875 & to 51 \\
\hline 1877 & to 5 \\
\hline 1879 & to 53 \\
\hline 1879 & to 6 \\
\hline 1880 & to 12 \\
\hline 1880 & to 47 \\
\hline 1884 & to 10 \\
\hline 1884 & to 84 \\
\hline 1885 & to 52 \\
\hline 1885 & to 9 \\
\hline 1887 & to 14 \\
\hline 1888 & to 28 \\
\hline 1888 & to 72 \\
\hline 1889 & to 59 \\
\hline 1889 & to 72 \\
\hline 1892 & to 86 \\
\hline 1894 & to 41 \\
\hline 1895 & to 8 \\
\hline 1898 & to 86 \\
\hline 1899 & to 37 \\
\hline 1903 & to 83 \\
\hline 1910 & to 2 \\
\hline 1910 & to 69 \\
\hline 1911 & to 15 \\
\hline 1913 & to 38 \\
\hline 1913 & to 65 \\
\hline 1913 & to 71 \\
\hline 1917 & to 42 \\
\hline 1918 & to 1 \\
\hline 1920 & to 29 \\
\hline 1923 & to 35 \\
\hline 1923 & to 57 \\
\hline 1930 & to 26 \\
\hline 1932 & to 32 \\
\hline 1932 & to 34 \\
\hline 1935 & to 11 \\
\hline
\end{tabular}




\begin{tabular}{lll} 
Plexiglas & 1935 & to 31 \\
Magnetic tape recorder & 1935 & to 62 \\
Colour photography & 1935 & to 82 \\
Television & 1936 & to 16 \\
Catalytic cracking & 1937 & to 70 \\
Helicopter & 1938 & to 20 \\
Fluorescent lamp & 1938 & to 56 \\
Polyethylene & 1939 & to 21 \\
Penicillin & 1942 & to 27 \\
Guided missiles & 1942 & to 30 \\
Jet airplane & 1942 & to 43 \\
DDT & 1942 & to 45 \\
Silicones & 1943 & to 24 \\
Ball-point pen & 1945 & to 13 \\
Streptomycin & 1946 & to 44 \\
Automatic transmission (passenger cars) & 1948 & to 55 \\
Sulzer loom & 1950 & to 22 \\
Xerography & 1950 & to 25 \\
Power steering (passenger cars) & 1951 & to 17 \\
Electronic computer & 1951 & to 18 \\
Transistor & 1951 & to 23 \\
Continuous casting of steel & 1952 & to 58 \\
Oxygen steel making & 1953 & to 68 \\
Numerically controlled machine tools & 1955 & to 49 \\
Nuclear energy & 1956 & to 33 \\
Integrated circuit & 1961 & to 64 \\
Laser & 1967 & to 73 \\
Video cassette recorder & 1970 & to 74 \\
Micro-processor & 1971 & to 63 \\
\hline
\end{tabular}

